\title{
Interleukin-23 Receptor Complex
}

National Cancer Institute

\section{Source}

National Cancer Institute. Interleukin-23 Receptor Complex. NCI Thesaurus. Code C147560.

A heterodimeric complex composed of interleukin-12 receptor subunit beta-1 and interleukin-23 receptor. This receptor complex binds to interleukin-23, which activates the JAK-STAT signaling pathway and modulates the activation of T-lymphocytes, natural killer cells and some myeloid lineage cells. 